\title{
PENGARUH ELEKTROLISER TERHADAP KEPEKAAN BAHAN BAKAR PADA MESIN DIESEL 1 SILINDER 20 HP
}

\author{
Sutomo, Murni, Senen, Rahmat \\ Program Diploma III Teknik Mesin \\ Fakultas Teknik Universitas Diponegoro
}

\begin{abstract}
Sutomo, Murni, Senen, Rahmat, Electrolyzer is development of a electrolysis technology to produce HHO gas, or Brown's gas. Diesel engine use solar (diesel oil) as combustion's material to produce thermal energy and oxidation and will be changed to mechanic energy. The base product of thermal energy by oxidation diesel oil, is would like to use electrolyzer to produce HHO and insert to the fuel combustion. Because HHO is a reactive gas, so in our research we hopeful will increase the thermal energy in combustion process and decrease the diesel oil consumption. The result of this research is the BSFC (Brake Shat Fuel Consumption) will decrease $2.5 \%$ up to $3.2 \%$.
\end{abstract}

Key word: electrolyzer, diesel engine, BSFC

\section{PENDAHULUAN}

Motor adalah gabungan dari alat-alat yang bergerak (dinamis) yang bila bekerja dapat menimbulkan tenaga/energi. Sedangkan pengertian motor bakar adalah motor yang sumber tenaganya diperoleh dari hasil pembakaran gas di dalam ruang bakar.

Tenaga yang dihasilkan oleh motor adalah berasal dari adanya pembakaran gas di dalam ruang bakar. Karena adanya pembakaran gas, maka timbullah panas. Dan panas ini mengakibatkan gas mengembang/ekspansi. Pembakaran dan pengembangan gas ini terjadi di dalam ruang bakar yang sempit dan tertutup (tidak bocor) dimana bagian atas dan samping kiri kanan dari ruang bakar adalah statis/tidak bergerak, sedangkan yang dinamis atau bisa bergerak adalah bagian bawah, yakni piston sehingga piston dengan sendirinya akan terdorong ke bawah dengan kekuatannya gas yang terbakar dan mengembang tadi. Pada saat piston terdorong ke bawah ini akan membawa tenaga yang sangat dasyat dan tenaga ini yang dimaksud dengan tenaga motor.

Motor diesel sendiri adalah jenis motor bakar yang merupakan salah satu mesin konversi energi thermal yang diubah menjadi energi mekanik dengan proses pembakaran dalam silinder. Torak (piston) yang bergerak secara translasi/bolakbalik di dalam silinder mengkompresikan udara sehingga menaikkan temperatur dan tekanan, kemudian bahan bakar dikabutkan dalam silinder tersebut. Karena suhu dan tekanan yang sangat tinggi menyebabkan bahan bakar yang dikabutkan oleh nozel akan terbakar dengan sendirinya (compression ignition engines) dan terjadilah proses ekspansi yang mendorong piston. Mesin diesel termasuk jenis pembakaran dalam (internal combustion engines), karena pembakaran terjadi di dalam mesin itu sendiri.

Diharapkan HHO dari elektroliser akan meningkatkan panas pada proses pembakaran sehingga keperluan bahan bakar akan turun (menghemat bahan bakar).

\section{TINJAUAN PUSTAKA}

Prinsip Kerja Motor Diesel 4 Langkah

Prinsip kerja mesin diesel adalah gerakan bolak-balik dari torak hasil pembakaran yang membentuk siklus yaitu urutan kejadian yang berulang secara teratur dengan urutan yang sama. Siklus kerja dari motor diesel adalah sebagai berikut:

- Langkah Pengisian

Torak bergerak dari TMA ke TMB. Katup masuk terbuka dan katup buang tertutup karena isapan torak udara mengalir ke dalam silinder melalui katup masuk. Pada saat pemasukan udara ini di dalam silinder tekanannya lebih rendah dari tekanan atmosfer. Setelah sampai di TMB katup masuk tertutup.

- Langkah Kompresi

Pada langkah ini torak bergerak dari TMB ke TMA. Kedua katup tertutup karena gerakan torak ke atas. Udara yang berada di dalam silinder dikompresikan.

- Langkah Ekspansi/Kerja

Torak bergerak dari TMA ke TMB. Kedua katup masih dalam keadaan tertutup. Saat sebelum torak sampai di TMA atau sebelum langkah kompresi bahan bakar dikabutkan ke dalam ruang bakar. Bahan bakar tersebut langsung terbakar dengan sendirinya karena udara pembakar di dalam ruang bakar itu sudah bertemperatur sangat tinggi. Karena pembakaran itu temperatur dan tekanannya naik, gas pembakaran berekspansi dan mendorong torak ke bawah untuk melakukan kerja mekanis menggerakkan poros engkol.

- Langkah Buang Torak bergerak dari TMB ke TMA. Pada proses ini katup masuk tertutup dan katup buang terbuka. Dalam gerakan torak ke atas menuju 
TMA gas hasil pembakaran akan terdorong keluar melalui katup pembuangan. Setelah torak menyelesaikan langkah ini sampai di TMA katup pembuangan tertutup dan katup masuk terbuka, siap melakukan langkah pengisian lagi.

\section{Pembakaran Bahan Bakar}

Pembakaran adalah reaksi kimia, yaitu elemen tertentu dari bahan bakar setelah dinyalakan dan digabungkan dengan oksigen menimbulkan panas sehingga menaikkan suhu dan tekanan gas. Elemen mampu bakar yang utama adalah karbon dan hidrogen, elemen mampu bakar yang lain yang tidak disukai dan terkandung dalam jumlah sedikit adalah belerang. Oksigen yang diperlukan untuk pembakaran diperoleh dari udara, yang merupakan campuran dari oksigen dan nitrogen.

Nitrogen adalah gas lembam dan tidak berpartisipasi dalam proses pembakaran. Selama proses pembakaran, butiran bahan bakar dipisahkan menjadi elemen komponennya, yaitu hidrogen dan karbon dan masing-masing elemen bergabung dengan oksigen dari udara secara terpisah. Untuk pembakaran diperlukan udara. Jumlah udara yang diperlukan dapat dihitung dengan metode di bawah ini.

Nilai pembakaran bajan bakar (Qe) dapat dihitung dengan rumus :

$$
\begin{aligned}
& \mathrm{Qe}=81(\mathrm{C})+300(\mathrm{H})-26(\mathrm{O})-600(9 \mathrm{H} / 100) \\
\mathrm{Qe} & =81(86)+300(13)-26(1)-600(9.13 / 100) \\
& =6966+3900-26-702 \\
& =10138 \mathrm{kkal} / \mathrm{kg}
\end{aligned}
$$

Kebutuhan udara pembakar teoritis (Lo') dengan komposisi $21 \% \mathrm{O}_{2}$

$$
\begin{aligned}
& \text { Lo' }=\frac{100}{21}\left(\frac{2}{12}+\frac{\mathbb{E}}{4}-\frac{\theta}{\mathrm{a} 2}\right) \text { moles/kg bh.bk } \\
& \mathrm{Lo}^{\prime}=\frac{100}{21}\left(\frac{0.86}{12}+\frac{0.12}{4}-\frac{0.01}{22}\right) \\
& =0.4949 \text { moles } / \mathrm{kg} \text { bh.bk }
\end{aligned}
$$

Pemakaian volume udara teoritis (Lo”) dapat dihitung dengan rumus:

$$
\text { Lo” = 24.4 Lo' } \mathrm{m}^{3} / \mathrm{kg} \text { bh.bk }
$$

$$
\begin{aligned}
\text { Lo” } & =24.4 \times 0.4945 \\
& =12.0658 \mathrm{~m}^{3} / \mathrm{kg} \text { bh.bk }
\end{aligned}
$$

Pemakaian berat udara teoritis (Lo) dapat dihitung dengan rumus:

$$
\text { Lo = 28.95 Lo’ Kg udara/kg bh.bk }
$$

$$
\begin{aligned}
\text { Lo } & =28.95 \times 0.4945 \\
& =14.3158 \mathrm{~kg} \text { udara } / \mathrm{kg} \text { bh.bk }
\end{aligned}
$$

Pemakaian udara pembakar sebenarnya (L) dapat dihitung dengan rumus:

$$
\alpha=\frac{\mathbb{L}}{\mathbb{L} o}
$$

Dimana, $\alpha=$ koefisien kelebihan udara sebenarnya: 1.3 - 1.7; diambil 1.7

$$
\begin{aligned}
& \text { Sehingga : } \\
& \begin{aligned}
\text { L } & =\alpha . \text { Lo } \\
& =1.7 \times 14.3158 \\
& =24.337 \mathrm{~kg} / \mathrm{kg} \text { bh.bk }
\end{aligned}
\end{aligned}
$$

\section{Elektroliser \\ Pengertian Elektroliser}

Elektroliser adalah suatu mesin atau alat yang memisahkan air menjadi hidrogen dan oksigen sehingga menghasilkan brown gas. Kadang disebut pula dengan nama "hydrogen generator".

Elektrolisis adalah proses penguraian molekul menjadi unsur-unsur asalnya dengan mengaliri arus listrik. Sedangkan elektrolisis air adalah proses penguraian molekul air menjadi unsur-unsur asalnya dengan mengaliri arus listrik, proses elektrolisa ini menghasilkan gas HHO. Gas ini ada juga yang menamakan gas rhodes atau brown gas.

\section{Prinsip Kerja Alat Brown Gas}

Gas Brown yang dinamakan sesuai dengan penemunya, Yull Brown, berkebangsaan Australia, adalah campuran gas hidrogen-hidrogen-oksigen yang dihasilkan dari sistem elektrolisa atau penguraian cairan. Dalam tabung elektrolisa itu dipasang kumparan magnetik untuk memecahkan campuran air destilasi dan soda kue hingga menjadi campuran gas hidrogen-hidrogen-oksigen (HHO). Hidrogen bersifat eksplosif dan okesigen mendukung pembakaran. Gas HHO dalam tabung elektrolisa ini dialirkan melalui selang masuk ke ruang bakar mesin dan akan bercampur dengan gas hidrokarbon dari BBM. Dengan cara ini BBM dapat dihemat dalam tingkat yang signifikan.

Dengan masuknya brown gas ke dalam ruang bakar mesin, maka secara langsung akan menaikkan tingkat atau angka oktan bahan bakar. Angka oktan adalah suatu besaran berupa banyaknya bahan bakar yang dapat ditekan (compressed) sebelum terbakar. Dengan meningkatnya angka oktan, tenaga yang ditimbulkan akan lebih kuat, oleh karena pembakaran menjadi lebih sempurna.

Prinsip kerja dari alat brown gas ini sangat sederhana yaitu hanya dengan menambahkan gas HHO (Hidrogen-Hidrogen-Oksigen). Alat yang disebut elektroliser ini menghasilkan HHO (2 parts Hydrogen + 1 Oxygen) gas yang sangat mudah terbakar yang kemudian HHO ini dimasukkan ke intake manifold pada kendaraan bermotor. Dengan adanya campuran BBM + HHO yang kaya ini memungkinkan pembakaran menjadi lebih sempurna sehingga BBM menjadi efisien.

Terbentuknya HHO adalah adanya kombinasi antara tiga faktor yang bekerja.

- Arus listrik searah (DC) yang mengalir melalui tiga komponen yang bekerja yaitu kawat elektroda. 
- Putaran magnet (Magnitude Vortex) yang ditimbulkan oleh elektroda tersebut.

- Tekanan udara (Vacuum) yang berasal dari mesin itu sendiri.

\section{METODOLOGI}

Mesin diesel terdiri atas beberapa komponen/bagian yang mempunyai beberapa fungsi dan saling menunjang satu dengan yang lainnya. Adapun sistem penunjang yang dimaksud adalah :

- $\quad$ Sistem bahan bakar pada mesin diesel.

- Sistem pelumasan pada mesin diesel

- $\quad$ Sistem pendinginan pada mesin diesel.

\section{Perawatan Elektroliser}

Sebelum melakukan perawatan, pastikan mesin dalam keadaan mati. Selain itu pastikan pula botol elektroliser tidak tersambung dengan sirkuit (tegangan aki) 12 volt. Tengok botol elektrolisa setiap kali mesin dioperasikan. Perawatan bagi botol elektroliser sangat sederhana, yaitu hanya perlu diisi ulang air distilnya. Jika ada dari komponen ini yang mengalami kerusakan atau masalah seperti longgar dan sebagainya, maka kencangkan atau mengganti dengan yang baru.

Komponen Elektroliser (Replacement Parts)

\begin{tabular}{cll}
\hline No. & \multicolumn{1}{c}{ Item } & Jumlah \\
\hline 1 & Tabung kaca stainless & 2 buah \\
2 & Accu 12 volt & 1 buah \\
3 & Ampere meter & 1 buah \\
4 & Saklar & 1 buah \\
5 & Selang vacuum & 2 meter \\
6 & Lbow & 1 buah \\
7 & Tphenumatic & 1 buah \\
8 & Bubbler & 1 buah \\
9 & Air accu & 3 botol \\
10 & Soda kue & $1 / 4 \mathrm{~kg}$ \\
11 & Katup searah & 1 buah \\
12 & Kabel listrik & $4 \mathrm{~m}$ \\
\hline
\end{tabular}

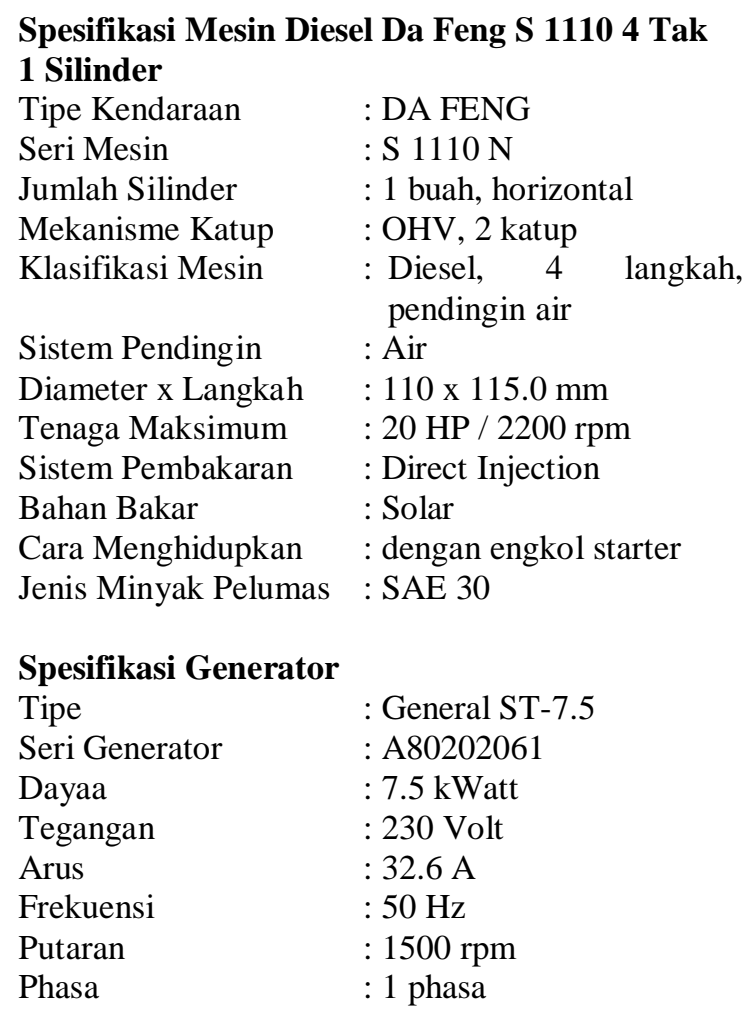

\section{HASIL DAN PEMBAHASAN}

Berdasarkan pengalaman peneliti sebelumnya pada pengujian ini dilakukan mengambil suhu bahan bakar pada suhu $50^{\circ} \mathrm{C}$ dengan tegangan dijaga tetap 220 Volt dengan mengatur putaran mesin diesel. Sehingga didapatkan hasil data seperti pada tabel 1 dan tabel 2 serta tabel 3 yang menginformasikan bahwa pemakaian elektroliser akan dapat menurunkan keperluan pemakaian bahan bakar dikarenakan tambahan gas HHO yang mengakibatkan peningkatan panas hasil pembakaran bahan bakar sehingga lebih menghemat bahan bakar.

Tabel 1. Data pengujian konsumsi solar tanpa elektroliser pada temperatur $50^{\circ} \mathrm{C}$ dengan tegangan 220 Volt

\begin{tabular}{|c|c|c|c|c|c|}
\hline No & Beban & Bahan Bakar (ml) & Arus (Amper) & Waktu (menit) & Rata-rata (meter) \\
\hline \multirow{3}{*}{1} & \multirow{3}{*}{ Stationer } & \multirow{3}{*}{100} & \multirow[t]{3}{*}{ 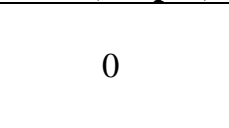 } & $10: 46$ & \multirow{3}{*}{$10: 11$} \\
\hline & & & & $9: 43$ & \\
\hline & & & & $10: 05$ & \\
\hline \multirow{3}{*}{2} & \multirow{3}{*}{$1 \mathrm{Kw}$} & \multirow{3}{*}{100} & \multirow{3}{*}{4} & $8: 39$ & \multirow{3}{*}{ 8:07 } \\
\hline & & & & $8: 05$ & \\
\hline & & & & $7: 37$ & \\
\hline \multirow{3}{*}{3} & \multirow{3}{*}{$2 \mathrm{Kw}$} & \multirow{3}{*}{100} & \multirow{3}{*}{8} & $5: 25$ & \multirow{3}{*}{$5: 24$} \\
\hline & & & & 5:09 & \\
\hline & & & & $5: 40$ & \\
\hline \multirow{3}{*}{4} & \multirow{3}{*}{$3 \mathrm{Kw}$} & \multirow{3}{*}{100} & \multirow{3}{*}{12} & $4: 57$ & \multirow{3}{*}{$5: 09$} \\
\hline & & & & $5: 26$ & \\
\hline & & & & 5:04 & \\
\hline
\end{tabular}




\begin{tabular}{|c|c|c|c|c|c|}
\hline No & Beban & Bahan Bakar (ml) & Arus (Amper) & Waktu (menit) & Rata-rata (meter) \\
\hline \multirow{3}{*}{5} & \multirow{3}{*}{$4 \mathrm{Kw}$} & \multirow{3}{*}{100} & \multirow{3}{*}{16} & $4: 28$ & \multirow{3}{*}{$4: 13$} \\
\hline & & & & $4: 11$ & \\
\hline & & & & 4:02 & \\
\hline \multirow{3}{*}{6} & \multirow{3}{*}{$5 \mathrm{Kw}$} & \multirow{3}{*}{100} & \multirow{3}{*}{20} & $3: 30$ & \multirow{3}{*}{$3: 26$} \\
\hline & & & & $3: 25$ & \\
\hline & & & & $3: 23$ & \\
\hline \multirow{3}{*}{7} & \multirow{3}{*}{$5.5 \mathrm{Kw}$} & \multirow{3}{*}{100} & \multirow{3}{*}{22} & 3:09 & \multirow{3}{*}{$3: 10$} \\
\hline & & & & 3:09 & \\
\hline & & & & $3: 23$ & \\
\hline \multirow{3}{*}{8} & \multirow{3}{*}{$6 \mathrm{Kw}$} & \multirow{3}{*}{100} & \multirow{3}{*}{24} & $3: 23$ & \multirow{3}{*}{ 3:06 } \\
\hline & & & & $3: 03$ & \\
\hline & & & & $2: 53$ & \\
\hline
\end{tabular}

Tabel 2. BSFC (Brake Shat Fuel Consumption) solar tanpa elektrolis

\begin{tabular}{ccccccc}
\hline $\begin{array}{c}\text { Temperatur } \\
\left({ }^{\mathbf{0}} \mathbf{C}\right)\end{array}$ & Beban & $\begin{array}{c}\text { Arus } \\
(\mathbf{A})\end{array}$ & $\begin{array}{c}\text { Waktu } \\
\text { (menit) }\end{array}$ & $\begin{array}{c}\text { Konsumsi } \\
\text { Bahan Bakar } \\
(\mathbf{l t} / \mathbf{j a m})\end{array}$ & $\begin{array}{c}\text { Beban } \\
(\mathbf{k W})\end{array}$ & $\begin{array}{c}\text { BSFC } \\
(\mathbf{l t} / \mathbf{k w h})\end{array}$ \\
\hline & Stationer & 0 & 10.18889 & 0.588876772 & - & - \\
& $1 \mathrm{~kW}$ & 4 & 8.116667 & 0.739219713 & 0.926 & 0.798293426 \\
& $2 \mathrm{~kW}$ & 8 & 5.411111 & 1.108829569 & 1.853 & 0.598396961 \\
50 & $3 \mathrm{~kW}$ & 12 & 5.15 & 1.165048544 & 2.779 & 0.419233013 \\
& $4 \mathrm{~kW}$ & 16 & 4.227778 & 1.419185283 & 3.705 & 0.38304596 \\
& $5 \mathrm{~kW}$ & 20 & 3.311111 & 1.812080537 & 4.632 & 0.37728622 \\
& $5.5 \mathrm{~kW}$ & 22 & 3.166667 & 1.894736842 & 5.095 & 0.371881618 \\
& $6 \mathrm{~kW}$ & 24 & 3.105556 & 1.932021467 & 5.558 & 0.347610915 \\
\hline
\end{tabular}

Tabel 3. BSFC (Brake Shat Fuel Consumption) solar dengan elektrolis

\begin{tabular}{ccccccc}
\hline $\begin{array}{c}\text { Temperatur } \\
\left({ }^{\mathbf{0}} \mathbf{C}\right)\end{array}$ & Beban & $\begin{array}{c}\text { Arus } \\
\text { (A) }\end{array}$ & $\begin{array}{c}\text { Waktu } \\
\text { (menit) }\end{array}$ & $\begin{array}{c}\text { Konsumsi } \\
\text { Bahan Bakar } \\
\text { (lt/jam) }\end{array}$ & $\begin{array}{c}\text { Beban } \\
(\mathbf{k W})\end{array}$ & $\begin{array}{c}\text { BSFC } \\
\text { (lt/kwh) }\end{array}$ \\
\hline & Stationer & 0 & 10.18889 & 0.55687476 & - & - \\
& $1 \mathrm{~kW}$ & 4 & 8.116667 & 0.65790554 & 0.926 & 0.7104811 \\
& $2 \mathrm{~kW}$ & 8 & 5.411111 & 0.93141684 & 1.853 & 0.5026534 \\
50 & $3 \mathrm{~kW}$ & 12 & 5.15 & 1.04854369 & 2.779 & 0.3773097 \\
& $4 \mathrm{~kW}$ & 16 & 4.227778 & 1.24888305 & 3.705 & 0.3370804 \\
& $5 \mathrm{~kW}$ & 20 & 3.311111 & 1.59463087 & 4.632 & 0.344264 \\
& $5.5 \mathrm{~kW}$ & 22 & 3.166667 & 1.66736842 & 5.095 & 0.3272558 \\
& $6 \mathrm{~kW}$ & 24 & 3.105556 & 1.71949911 & 5.558 & 0.3093737 \\
\hline
\end{tabular}

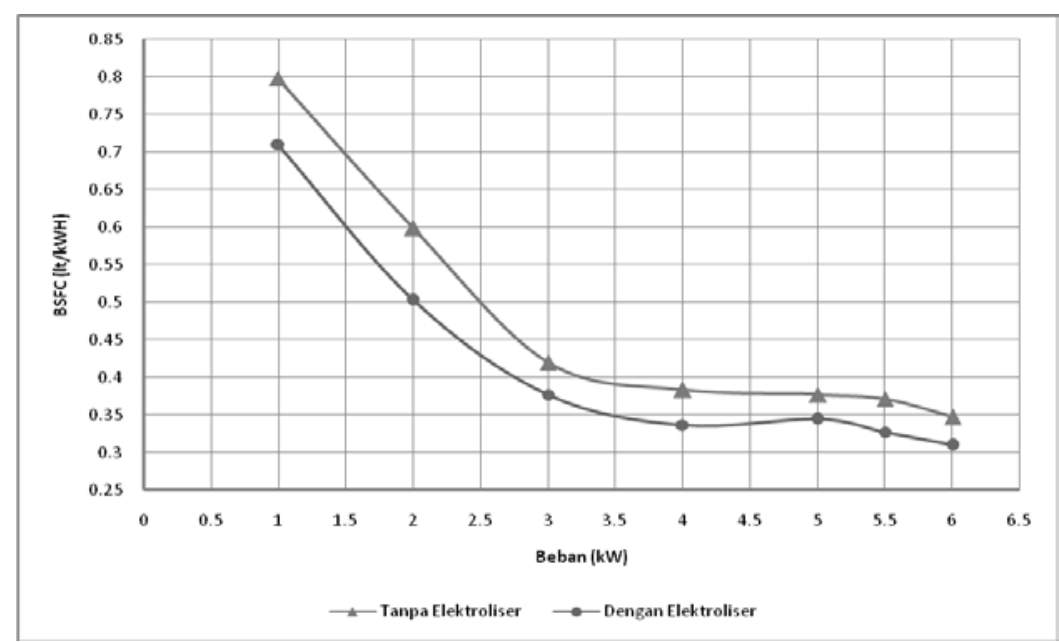

Grafik Perbandingan BSFC tanpa elektroliser vs dengan elektroliser 
Dari grafik di atas terlihat bahwa mesin yang menggunakan unit elektroliser BSFC lebih sedikit mengkonsumsi bahan bakar dibandingkan dengan yang tidak menggunakan unit elektroliser.

BSFC antara menggunakan elektroliser dan tanpa elektroliser pada suhu $50^{\circ} \mathrm{C}$ paling rendah adalah pada beban $6 \mathrm{~kW}$ dengan penghematan sebesar $12.35955 \%$.

Berdasarkan grafik BFSC tanpa elektroliser dan dengan elektroliser pada suhu $50^{\circ} \mathrm{C}$, semuanya menunjukkan bahwa pada meningkatnya beban akan meningkatkan penghematan bahan bakar setiap kWH-nya, ditambah lagi dengan penambahan elektroliser generator gas $\mathrm{HHO}$ akan mengakibatkan pembakaran lebih sempurna lagi sebab turunnya viskositas dan densitas lebih memungkinkan kesempurnaan proses pembakaran sehingga dicapai penghematan bahan bakar 11$12 \%$.

\section{KESIMPULAN DAN SARAN}

Berdasarkan hasil penelitian ini, maka dapat disimpulkan sebagai berikut :

- Semakin tinggi suhu bahan bakar semakin turun viskositas dan densitasnya sehingga memungkinkan lebih reaktif dalam proses pembakaran bahan bakar.

- Elektroliser yang menghasilkan gas HHO dapat menaikkan kandungan cetana dalam bahan bakar solar sehingga pembakarannya dapat lebih sempurna selanjutnya bahan bakan dapat dihemat.

- Elektroliser juga mengakibatkan suara mesin lebih halus dan mengurangi muatan polusi sebab proses pembakaran dapat lebih sempurna serta mengurangi karbon deposit di ruang bakar.

- Dengan pemanasan bahan bakar pada suhu $50^{\circ} \mathrm{C}$, pemakaian elektroliser akan meningkatkan penghematan bahan bakar 11$12 \%$.

- Berdasarkan pengamatan perilaku di dalam penelitian ini maka kami menyarankan sebagai berikut:

- Penggunaan elektroliser dapat digunakan untuk sepeda motor, mobil, truk dan lain-lain.

- Pada penelitian untuk kapasitas HHO yang lebih besar supaya dicapai pembakaran yang lebih sempurna.

- Pemanas bahan bakar sebaiknya menggunakan pemanas yang berkualitas baik, yang tahan terhadap solar yang dipanaskan hingga suho $70^{\circ} \mathrm{C}$.

- Menjaga tegangan yang dihasilkan generator tetap pada 220 volt dengan menaikkan atau menurunkan putaran mesin diesel.

- Periksa sambungan-sambungan selang bahan bakar dari kebocoran.
- Penempatan elektroliser diletakkan sejauh mungkin dari sumber panas, jika kurang yakin berilah pelindung dari alumunium foil.

- Jangan menyalakan korek api atau merokok di depan keluaran elektroliser karena elektrolisa air menghasilkan gas yang mudah terbakar.

- Gunakanlah air distilasi sebagai larutan elektrolit yang dipakai untuk elektrolisa.

- Penambahan baking soda/soda kue tidak lebih dari $1 / 2$ sendok the, dan tambahkan sedikit demi sedikit kalau gelembung yang dihasilkan masih sedikit, penambahan baking soda yang terlalu banyak akan menimbulkan panas yang berlebihan pada tabung elektroliser.

- Mengganti air distilasi dalam botol elektroliser setiap 2 atau 4 minggu sekali.

\section{DAFTAR PUSTAKA}

1. Arismunandar, Wiranto, dan Tsuda, Koichi. 2002. Motor Diesel Putan Tinggi. Jakarta : Pradya Paramita.

2. Hidayatullah, Poempida, dan Mustari, F. 2008. Rahasia Bahan Bakar Air. Jakarta : Cahaya Insan Suci.

3. Maleev, V.L. 1986. Operasi dan Pemeliharaan Mesin Diesel. Jakarta : Erlangga.

4. Manual Book. Diesel Engine Operation Manual.

5. Petrovsky, N. 1968. Marine Internal Combusting Engine. Moscow : Mir Publisher.

6. Sukardjo. 1989. Kimia Fisika. Yogyakarta : FPMIPA IKIP. 